\title{
Human response to the thermal indoor environment created by a radiant, and a combined radiant and convective cooling system
}

\author{
Ongun B. Kazanci ${ }^{l, *}$, Dolaana Khovalyg ${ }^{1}$, Takayoshi Iida $^{2}$, Yoshitaka Uno $^{2}$, Tomo-oki Ukiana ${ }^{2}$, Bjarne W. Olesen ${ }^{l}$ \\ ${ }^{1}$ International Centre for Indoor Environment and Energy - ICIEE, Department of Civil Engineering, \\ Technical University of Denmark, Nils Koppels Allé, Building 402, 2800 Kgs. Lyngby, Denmark \\ ${ }^{2}$ Mitsubishi Electric Corporation, 5-1-1 Ofuna, Kamakura, Kanagawa 247-8501, Japan
}

\begin{abstract}
This study reports the main findings from a series of human subject experiments, where the subjects were exposed to the different indoor environments created by different cooling systems. The studied systems were a radiant cooling system (chilled ceiling and mixing ventilation, CCMV), and a combined radiant and convective cooling system (radiant diffuse ceiling ventilation, RDCV). The experiments were conducted in a climate chamber under controlled conditions. The climate chamber was configured as a twoperson office room. 24 human subjects (12 female and 12 male) were chosen. The exposure lasted three hours and the participants were allowed to work on their own tasks (normal office work) during the exposure. The cooling load was $54 \mathrm{~W} / \mathrm{m}^{2}$ and the room temperature at a reference location was kept constant at $26^{\circ} \mathrm{C}$ (summer conditions). The results show that under both systems, whole body thermal sensation was between slightly warm and neutral (closer to neutral with the RDCV system), and the overall thermal acceptability was almost the same for both systems (close to clearly acceptable). The satisfaction of the human subjects with the thermal environment was very close under the two systems; between satisfactory and slightly satisfactory (closer to satisfactory). Air movement acceptability (slightly higher and closer to clearly acceptable with the RDCV system) was also very close with the two systems. The results of the human subject experiments agree well with the physical measurements of the thermal indoor environment and confirm that the studied systems created very similar thermal indoor environments.
\end{abstract}

\section{Introduction}

Buildings are often cooled by mechanical cooling systems, which have different energy use characteristics and create different thermal indoor environments. The created thermal indoor environment depends strongly on the chosen indoor terminal unit. Indoor terminal units are active building components that emit or remove heat and moisture to indoor spaces. Indoor terminal units mainly rely on convection (natural or forced), radiation or both [1].

Radiant heating and cooling systems have several benefits in terms of energy performance, operation, and thermal comfort, compared to the more conventional convective systems [2]. Due these benefits, the interest in radiant systems and their use is increasing world-wide.

Mainly due to this increasing interest and increasing use, several recent studies compared the thermal indoor environment created by radiant and convective systems by climate chamber studies [3], [4], [5] and by field studies [6], [7]. A recent literature review [8] focused on the thermal comfort resulting from radiant and all-air systems and concluded that there was a need for further studies to be able to provide a definitive conclusion on which system provides a more satisfactory thermal indoor environment.

The main objective of this study was to experimentally compare the performances of a radiant cooling system (radiant ceiling panels and mixing ventilation), and a combined radiant and convective cooling system (a novel combination of a different kind of ceiling panels and diffuse ceiling ventilation), in terms of the created thermal indoor environment, energy use and system operation, and human response (human subject experiments). The results of the thermal indoor environment, and energy use and system operation comparisons have been reported previously [9], [10]. This paper reports the main findings from the human subject experiments.

\section{Methods}

The experiments were carried out at one of the climate chambers (Chamber 5) at the International Centre for Indoor Environment and Energy (ICIEE), Technical University of Denmark (DTU). Two systems were tested,

* Corresponding author: Ongun Berk Kazanci, onka@byg.dtu.dk 
a chilled ceiling and mixing ventilation (CCMV) system, and a combined radiant and convective system (radiant diffuse ceiling ventilation system, RDCV).

Both systems were operated to keep a room temperature of $26^{\circ} \mathrm{C}$ during the experiments (corresponding to Category 2 of EN 15251:2007 [11]). The ventilation rate was determined according to Category 2 of $\mathrm{EN}$ 15251:2007 corresponding to two persons and a lowpolluting building.

The climate chamber had the dimensions of $4.12 \mathrm{~m} \mathrm{x} 4.2$ $\mathrm{m} \times 2.89 \mathrm{~m}$, corresponding to a floor area of $17.3 \mathrm{~m}^{2}$. For the purposes of this study, the climate chamber was configured as a two-person office room with the corresponding internal heat gains. Table 1 summarizes the internal heat gains and Fig. 1 shows the experimental setup in the climate chamber.

Table 1. Cooling load components and the corresponding total cooling load.

\begin{tabular}{|c|c|}
\hline Cooling load component & Load [W] \\
\hline Two occupants $(60 \mathrm{~W}$ each) & 120 \\
\hline Two computers $(18 \mathrm{~W}$ each) & 36 \\
\hline Lighting & 168 \\
\hline Heated window surface $\left(6.3 \mathrm{~m}^{2}, 33^{\circ} \mathrm{C}\right)$ & 353 \\
\hline Direct solar radiation on the floor & 250 \\
\hline Total cooling load & $54 \mathrm{~W} / \mathrm{m}^{2}$ \\
\hline
\end{tabular}

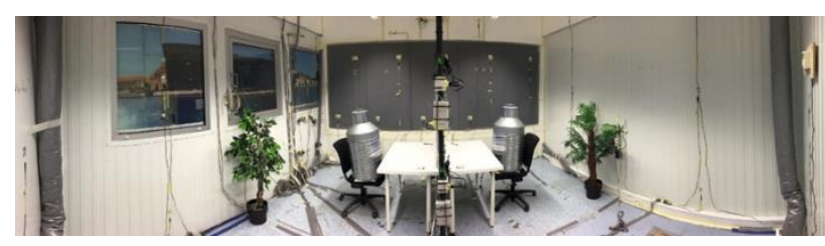

Fig. 1. Panoramic view of the experimental setup.

\subsection{Main characteristics of the radiant diffuse ceiling ventilation (RDCV) system}

In the RDCV system, the cold air was supplied into the plenum (between the suspended ceiling and the real ceiling of the climate chamber), which then diffused into the climate chamber. Room air was extracted through four exhausts in the corners at the floor level. Two of these exhausts were for the indoor unit (recirculation) and two of them were for the air-handling unit (fresh air).

The suspended ceiling consisted of thin metal panels of $0.6 \mathrm{~m} \times 0.6 \mathrm{~m}$. These metal panels were placed in rows so that there was a row of panels with holes and next to that, there was a row of panels without holes and so forth. In total, there were seven rows, four rows of panels with holes and three rows of panels without holes. These metal panels were cooled when there was cold air supply into the plenum, therefore creating a combined radiant and convective cooling effect through the ceiling. The supply air was a mixture of fresh and recirculated air $(26.5 \mathrm{~L} / \mathrm{s} \mathrm{\&}$ $48.1 \mathrm{~L} / \mathrm{s}$, respectively). Total airflow rate was $74.6 \mathrm{~L} / \mathrm{s}$, corresponding to $5.4 \mathrm{ACH}$. The supply airflow rate was constant and the temperature in the climate chamber was controlled by varying the supply air temperature. Fig. 2 shows a panoramic view of the ceiling with the RDCV system.

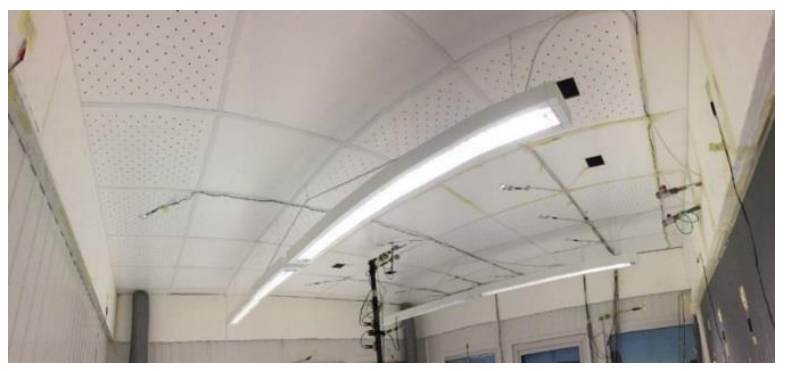

Fig. 2. Panoramic view of the ceiling with the RDCV system.

\subsection{Main characteristics of the chilled ceiling and mixing ventilation (CCMV) system}

This is the same system defined previously by Mustakallio et al. (2016). Fresh air was supplied to the climate chamber through two linear slot diffusers positioned in the middle of the ceiling. The airflow rate was $26.4 \mathrm{~L} / \mathrm{s}(1.9 \mathrm{ACH})$ and the supply air temperature was $16^{\circ} \mathrm{C}$ (design conditions). In both systems, the airflow rate was set slightly higher than the initial design condition of $26 \mathrm{~L} / \mathrm{s}$ to compensate for possible leakages. There were two exhausts located in the corners at the opposite side of the simulated windows. The exhausts were at the ceiling level.

The radiant ceiling panels had the dimensions of $1.2 \mathrm{~m} \mathrm{x}$ $0.6 \mathrm{~m}$ and covered $77 \%$ of the ceiling area. The water flow rate was $385 \mathrm{~L} / \mathrm{h}$. The supply and return water temperatures were 16.9 and $18.6^{\circ} \mathrm{C}$, respectively. Fig. 3 shows a panoramic view of the ceiling with the CCMV system.

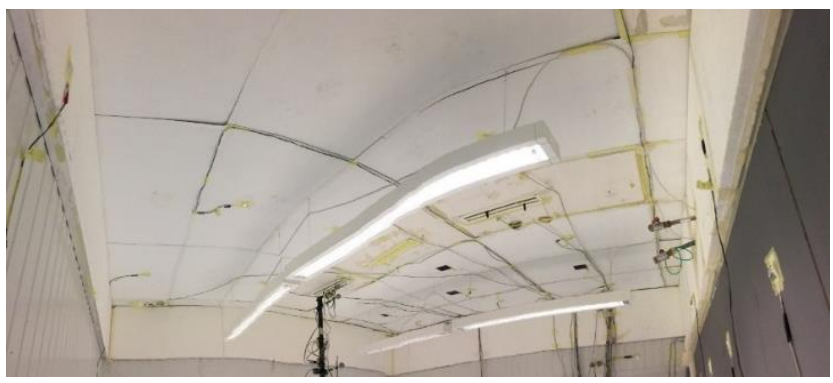

Fig. 3. Panoramic view of the ceiling with the CCMV system.

\subsection{Experimental procedure}

The human subjects consisted of healthy university students of different nationalities. There were 24 participants in total (12 female and 12 male).

The subjects were exposed first to RDCV system and then to the CCMV system at a later date.

Before the experiments, the subjects were invited to an information session, where they were informed about the main purpose of the experiments, the location, and the duration of the sessions, and the dates. Guidance on pretest preparations were given (e.g. no strongly perfumed hygienic products or strong perfumes on the day of the 
experiment, no chewing gum, etc.). The subjects were also instructed on the exact clothing they had to wear. The subjects were also informed about the procedure during the experiments (no use of toilet, no talking to each other, etc.).

The subjects had to fill in a pre-questionnaire upon arrival and a post-questionnaire upon the completion of the experiment.

The exposure lasted for three hours and during the exposure, the participants were allowed to work on their own tasks (office work, sedentary). The subjects had to answer the main questionnaire nine times (every 20 minutes). They filled in the questionnaires through an online link that was distributed prior to the day of experiments.

The last main questionnaire was followed by the post questionnaire. At the end of the first and second hours of exposure, the human subjects had to step up and down the step-stairs. This activity lasted for three minutes and the duration was recorded. The step-stairs were introduced to the experiments to simulate real office condition as close to reality as possible and to obtain an average metabolic rate of 1.2 met during the entire exposure.

The experimenters guided the human subjects via a walkie-talkie throughout the entire exposure and told them when to fill in the questionnaires, when to start and stop stepping on the step-stairs, and so forth.

Table 2 shows the basic information regarding the participants and Table 3 shows the clothing information of the participants (calculated according to ISO 7730:2005 [12] and ISO 9920:2009 [13]).

Table 2. Basic information regarding the participants.

\begin{tabular}{|c|c|c|c|c|c|c|}
\hline & & $\begin{array}{c}\text { Age } \\
\text { [years] }\end{array}$ & $\begin{array}{c}\mathrm{H} \\
{[\mathrm{cm}]}\end{array}$ & $\begin{array}{c}W \\
{[k g]}\end{array}$ & BMI & $\begin{array}{c}\% \\
\text { body } \\
\text { fat }\end{array}$ \\
\hline \multirow{2}{*}{$\begin{array}{l}\text { Whole } \\
\text { group }\end{array}$} & Av & 26.3 & 170 & 67.7 & 23.4 & 24.2 \\
\hline & $\begin{array}{l}\text { Std } \\
\text { Dev }\end{array}$ & 5.3 & 9 & 11.9 & 2.8 & 8.7 \\
\hline \multirow[b]{2}{*}{ Males } & $\mathrm{Av}$ & 27.2 & 176 & 71.5 & 23.2 & 18.9 \\
\hline & $\begin{array}{l}\text { Std } \\
\text { Dev }\end{array}$ & 7.2 & 6 & 12.0 & 3.3 & 8.3 \\
\hline \multirow[b]{2}{*}{ Females } & $\mathrm{Av}$ & 25.5 & 164 & 64.0 & 23.6 & 29.6 \\
\hline & $\begin{array}{l}\text { Std } \\
\text { Dev }\end{array}$ & 1.8 & 8 & 10.8 & 2.3 & 5.1 \\
\hline
\end{tabular}

Table 3. Clothing information of the participants.

\begin{tabular}{|c|c|c|c|}
\hline & & clo (without chair) & clo (with chair) \\
\hline \multirow{2}{*}{$\begin{array}{l}\text { Whole } \\
\text { group }\end{array}$} & Av & 0.42 & 0.52 \\
\cline { 2 - 4 } & $\begin{array}{c}\text { Std } \\
\text { Dev }\end{array}$ & 0.06 & 0.06 \\
\hline \multirow{3}{*}{ Males } & Av & 0.43 & 0.53 \\
\cline { 2 - 4 } & $\begin{array}{c}\text { Std } \\
\text { Dev }\end{array}$ & 0.06 & 0.06 \\
\hline \multirow{3}{*}{ Females } & Av & 0.40 & 0.50 \\
\cline { 2 - 4 } & $\begin{array}{c}\text { Std } \\
\text { Dev }\end{array}$ & 0.05 & 0.05 \\
\hline
\end{tabular}

As a part of the physical measurements before the human subject experiments, there were also measurements carried out with a thermal manikin [9]. The average clothing worn by the human subjects and the clothing worn by the manikin were very close; manikin had 0.43 and 0.53 clo, without $\&$ with chair, respectively.

\subsection{Data analysis}

The data (replies from human subjects) obtained from the questionnaires were analysed statistically using a commercially available statistical software (JMP [14]).

The obtained data were tested for normality distribution using Shapiro-Wilk W test. Not normally distributed data were analysed using Wilcoxon Matched Pairs Test. The level of statistical significance was set to be 0.05 .

\section{Results and discussion}

The main results related to thermal comfort are presented and discussed in the following. Further results are available in [9].

The results presented include the answers to the questionnaires starting from the third questionnaire out of the nine questionnaires. The answers to the first two questionnaires were not included in the analysis presented here as this period was considered as the acclimatization period.

The results presented in the following are for the whole group (24 subjects).

Fig. 4 shows the results of overall (whole body) thermal sensation (median values are shown, bars indicate $25 \%$ and $75 \%$ quartiles, $3=$ HOT, $2=$ WARM, 1=SLIGHTLY WARM, $0=$ NEUTRAL, $-1=$ SLIGHTLY COOL, $-2=$ COOL, $-3=$ COLD). 


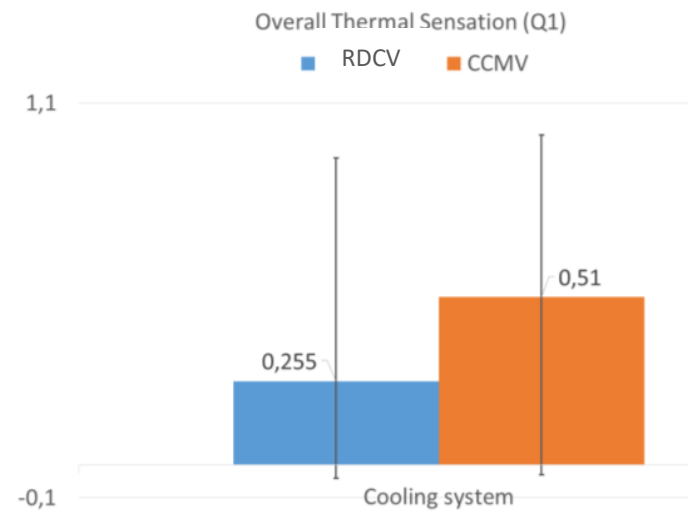

Fig. 4. Overall (whole body) thermal sensation.

Fig. 4 shows that the overall thermal sensation under both systems were close and that both systems created very similar thermal conditions and there was no statistically significant difference between the results. The CCMV system created conditions that were between slightly warm and neutral, while the RDCV system created conditions that were slightly closer to the neutral.

It can also be seen that both systems were designed for $26^{\circ} \mathrm{C}$ (PMV $=0.5$ under the given conditions) and the results confirm this, with the RDCV system creating conditions that are slightly closer to neutral.

Fig. 5 shows the results of overall (whole body) thermal acceptability (median values are shown, bars indicate $25 \%$ and $75 \%$ quartiles, $*$ denotes a statistically significant difference, $1=$ CLEARLY ACCEPTABLE, $0.01=$ JUST $\quad$ ACCEPTABLE, $\quad-0.01=$ JUST UNACCEPTABLE, $\quad-1=$ CLEARLY UNACCEPTABLE).

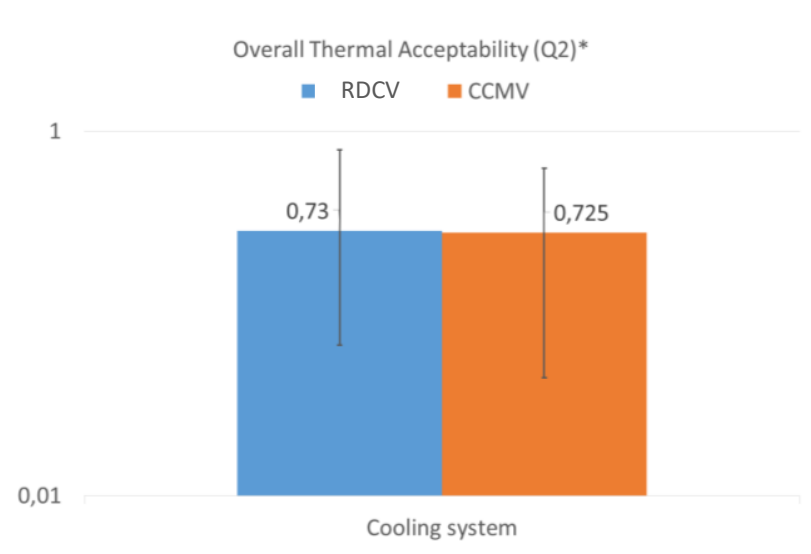

Fig. 5. Overall (whole body) thermal acceptability.

Fig. 5 shows that the overall thermal acceptability under both systems was almost the same and close to clearly acceptable. The range of $25 \%$ and $75 \%$ quartiles for the RDCV system are closer to the clearly acceptable. Even though statistical analysis showed a significant difference, this does not have an important implication, as the results are almost the same for two systems.
Fig. 6 shows the results of air movement acceptability (median values are shown, bars indicate $25 \%$ and $75 \%$ quartiles, * denotes a statistically significant difference, $1=$ CLEARLY ACCEPTABLE,
ACCEPTABLE, $-0.01=$ JUST UNACCEPTABLE,
-1=CLEARLY UNACCEPTABLE).

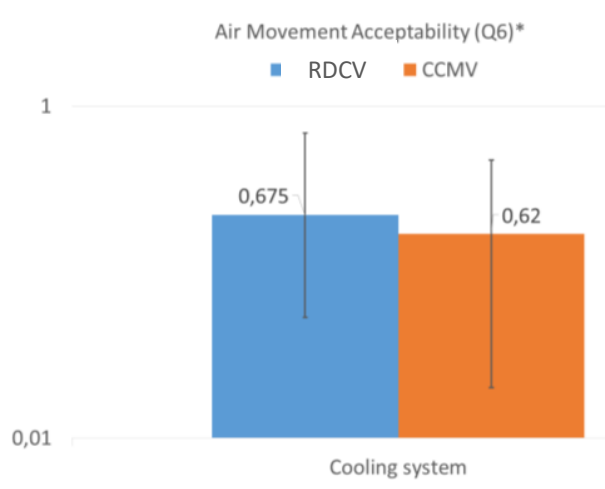

Fig. 6. Air movement acceptability.

Fig. 6 shows that the air movement acceptability was slightly higher and closer to clearly acceptable with the RDCV system (statistically significant difference; however, very close results). The $25 \%$ and $75 \%$ quartiles of the RDCV system are closer to the clearly acceptable.

Fig. 7 shows the results of thermal environment assessment (median values are shown, bars indicate $25 \%$ and $\quad 75 \%$ quartiles, $100=$ COMFORTABLE, 66.6=SLIGHTLY UNCOMFORTABLE, 33.3=UNCOMFORTABLE, $\quad 0=\mathrm{VERY}$ UNCOMFORTABLE).

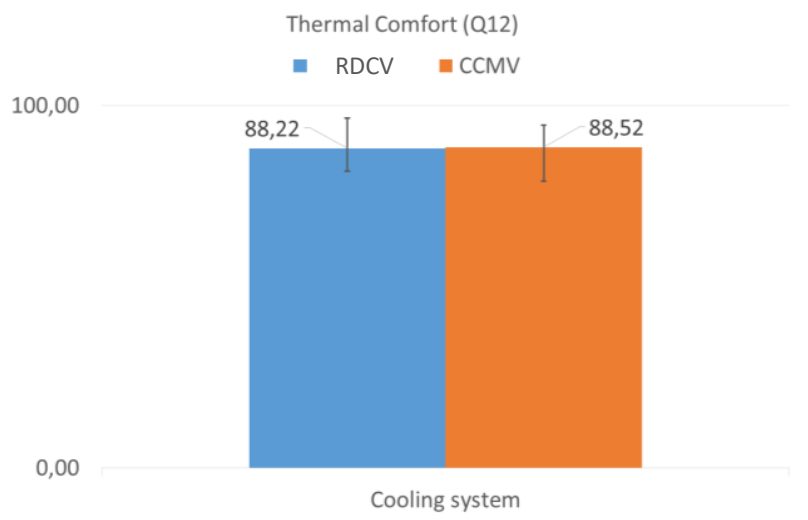

Fig. 7. Thermal environment assessment.

Fig. 7 shows that both systems created a thermal environment that was very close to comfortable and there was not a significant difference between the systems. This result is consistent with the results presented in Figs. 4 and 5 .

Fig. 8 shows the results of the satisfaction with the thermal environment (median values are shown, bars indicate 25\% and $\quad 75 \%$ quartiles, $\quad 100=$ SATISFACTORY, 


\section{6=SLIGHTLY \\ 33.3=DISSATISFACTORY, DISSATISFACTORY).}

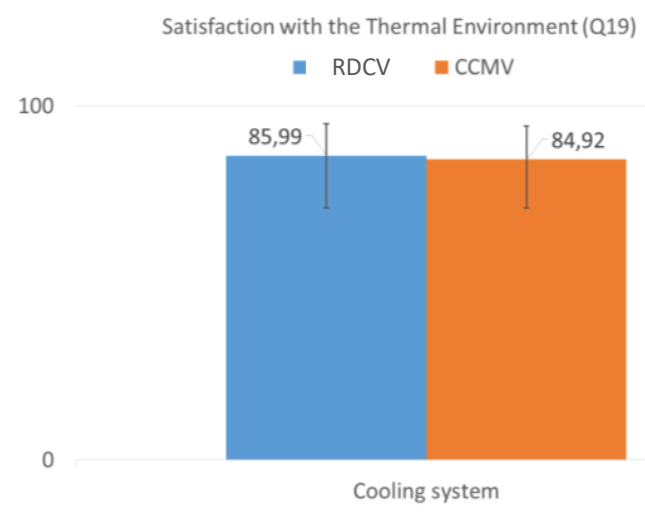

Fig. 8. Satisfaction with the thermal environment.

The results in Fig. 8 show that both systems resulted in a very similar satisfaction with the thermal environment. The results were between satisfactory and slightly satisfactory (closer to satisfactory). Although these results show a high satisfaction with the thermal indoor environment, they should be considered together with the comments provided by the subjects [9].

One of the comments received from the human subjects was the need for more fresh air (i.e. stuffy air complaints). This indicates that even though the ventilation rate was determined according to Category 2 of EN 15251:2007 corresponding to two persons and a low-polluting building, it was not enough. This is an interesting result and requires further investigations.

In addition to the results presented so far, two systems had similar effects on SBS symptoms (headache, nose, throat irritation, dry eyes, etc.) [9].

Since both systems created very similar thermal indoor environments, the final system selection in practice would depend on factors such as energy performance, costs (initial and operational), available space, control possibilities and so forth. A broader list of factors for indoor terminal unit selection is provided in [2].

\section{Conclusions}

Under both systems, whole body thermal sensation was between slightly warm and neutral (closer to neutral with the RDCV system), the overall thermal acceptability was almost the same for both systems and close to clearly acceptable. The satisfaction of the human subjects with the thermal environment was very close under the two systems; between satisfactory and slightly satisfactory (closer to satisfactory).

Air movement acceptability (slightly higher and closer to clearly acceptable with the RDCV system) was also very close with the two systems.
Previous studies [9], [10] showed that the two systems created very similar and uniform thermal indoor environments and flow fields in the chamber. This finding was confirmed by the results of the human subject experiments presented in this paper.

This study was financially supported by Mitsubishi Electric Corporation and by the International Centre for Indoor Environment and Energy (ICIEE), Technical University of Denmark (DTU). The authors would like to thank Nico Henrik Ziersen for his help with preparing the experimental setup.

\section{References}

[1] O. B. Kazanci, B. W. Olesen, Energy Procedia 6th International Building Physics Conference, IBPC 2015, 78, 2427-2432, (2015).

[2] O. B. Kazanci, PhD Thesis, (2016).

[3] Z. D. Bolashikov, P. Mustakallio, S. Kolencikova, K. Kostov, A. K. Melikov, R. Kosonen, Proceedings of 11th REHVA World Congress and the 8th International Conference on Indoor Air Quality, Ventilation and Energy Conservation in Buildings, (2013).

[4] P. Mustakallio, Z. Bolashikov, K. Kostov, A. Melikov, R. Kosonen, Build. and Env., 100, (2016).

[5] P. Mustakallio, Z. Bolashikov, L. Rezgals, A. Lipczynska, A. Melikov, R. Kosonen, Build. and Env., 123, (2017).

[6] T. Imanari, T. Omori, K. Bogaki, En. and Build., 30, (1999).

[7] G. Sastry, P. Rumsey, ASHRAE Journal, 56, (2014).

[8] C. Karmann, S. Schiavon, F. Bauman, Build. and Env., 111, (2017).

[9] O. B. Kazanci, D. Khovalyg, B. W. Olesen, Final Report, (2017).

[10] O. B. Kazanci, D. Khovalyg, I. Takayoshi, Y. Uno, T. Ukiana, B. W. Olesen, Proceedings of Roomvent \& Ventilation 2018, (2018).

[11] EN 15251, (2007).

[12] EN ISO 7730, (2005).

[13] ISO 9920, (2009).

[14] JMP, (2018). 